\title{
Family Involvement in the Implementation of Education in the Early Childhood Unit in Instilling Nationalism Values
}

\author{
Erni Sukmawati Dewi ${ }^{1, *}$ Darnowo $^{1}$ Yedi Kusmayadi $^{1}$ \\ ${ }^{1}$ Center for Development of Early Childhood Education and Community Education, Bandung, Indonesia \\ *Corresponding author. Email: erni_subhan@yahoo.co.id
}

\begin{abstract}
Regulation of Minister of Education and Culture, Republic of Indonesia, Number 30 of 2017 concerning Family Involvement in Education Unit explains that family has a strategic role in supporting the delivery of education to achieve national education goals, and the involvement of families in the education management requires synergy between education units, families and communities. This is in line with the thought of Ki Hajar Dewantoro, a popular educational activist, who stated that education is a shared responsibility between education units, families and communities known as the tri pusat pendidikan. The results of the preliminary study indicated that the early childhood education unit (ECCE units) had already engaged in family involvement, but its implementation was still not yet maximal, including: 1) the parents-and-teacher meetings were only carried out at the time of the distribution of children's development reports 2). The implementation of parent classes was still lacking in media and methods; and did not involve parents as resource persons, 3) Inspirational classes did not involve parents as resource persons; and methods were not varied, 4) Class performances were limited to the performance of children; and did not involve parents. To answer the above problems, the Center for Development of Early Childhood Education and Community Education, West Java, Indonesia, developed Family Involvement in Implementation Education in Early Childhood Education Units in Instilling Nationalism Value, to encourage ECCE units to seek parents involvement in various activities that support the educational process and embedding nationalism in students. It is an innovative pattern that reflects the synergy between the school, parents and the community. The contents of it include a description of the management of the family engagement program, and the optimization of family involvement to increase the awareness, role and ability of parents in supporting education and embedding children's nationalism. It is divided into 3 major stages, namely the stages of design, action, and the results stage for school-and-parents meetings, parent classes, inspirational classes, and classroom performances. Family Involvement in Implementation Education in Early Childhood Education Units in Instilling Nationalism Value aims to: 1) Increase the nationalism value of students, 2) increase the love of Indonesian culture, 3) Reduce individualistic attitudes, consumerism, in some communities, 4) Increase parents participation in teacher meetings, 4) Provide strengthening for students in growing the character and values of nationalism, 5) Increase parents knowledge, attitudes and skills in family education. The method used research and development method, through the collection, processing, analysis, and presentation of data carried out systematically and objectively accompanied by activities to develop a product to solve the problems faced. The method is considered suitable bearing in mind the purpose of developing the ECCE and community education models is not intended to find theories, but rather to produce or develop a product that can be used as an input for policy making, as well as a formula for improving the quality of education services, in this case family education services. This has been tested in 4 locations, Wiyata Bhakti Play Group in Purwakarta, POS PAUD Dewi Pramanik in Bandung Municipality, Golden Age Kindergarten in Subang, and Public Kindergarden in Cimahi Municipality. The products include model scripts, dictates (patriotism, diversity, nationality), and media (posters, flipcharts, discussion cards). The achievement of the family engagement program in ECCE units is supposed to have a positive impact on students by having the character of nationalism.
\end{abstract}

Keywords: family, early childhood education, nationalism 


\section{PRELIMINARY}

\subsection{Background}

Quality citizens are needed in the framework of national development in the future. To generate quality citizens requires a long path. It should begin from childhood. It is because children are a very important investment for the preparation of human resources (HR) in the future. Education is one among other ways to bring about quality citizens.

The instilling of nationalism value from an early age requires harmony between education carried out in the education unit or school and in the family environment. It is a prerequisite for the successful implementation of education. Its success will be even higher if supported by appropriate learning, using appropriate ways or methods in order to build an educational ecosystem conducive to children's education. More broadly, it is expected to encourage the growth of character, literacy culture and nationalism values of all ECCE unit members.

Regulation of Minister of Education and Culture Number 30 of 2017 (Minister of Education and Culture of Indonesian Republic, 2018) explains that family has a strategic role in supporting the delivery of education to achieve national education goals, and the involvement of families in the education management requires synergy between education units, families and communities. This is in line with the thought of Ki Hajar Dewantoro who stated that education is a shared responsibility between education units, families and communities known as the tri pusat pendidikan.

Based on the results of the preliminary study regarding the process of embedding nationalism in ECCE units, the following data were obtained: lack of media for embedding nationalism in schools, lack of cooperation between schools and families. Problems faced by families in instilling nationalism value in early childhood included not knowing how to convey, lack of understanding of nationalism, no media, and other environmental factors.

Other problems relating to the implementation of the family involvement program in ECCE units were as follows: 1) The participation of parents (both father and mother) in meeting organized by schools were still low (still dominated by the presence of mothers), and there had not been an alignment of education in school with those in houses, for example in terms of enforcing rules, 2) Parents' association as a place of parents representation in expressing their aspirations and hopes, was still very passive in order to initiate meetings with the school. So far, the association meeting with the school was still initiated by the school, 3) The teacher-and-parent meetings were mostly only attended by mothers of the students, 4) Invitations from schools to parents often did not suit the parents' free time. It is proven by the identification data which found that the reasons for the absence of parents in the meetings were due to conflicting time with work activities, no surrogate to look after other children at home, the distance from school to home was quite far, and having other necessity/being sick, 5) The parents mostly acted as listeners in meetings. The information conveyed was important, but the delivery method was still one-way, 6) The themes are supposed to be discussed in the meetings/ classes to increase their care and ability in educating children were child development, child intercommunication, parent-child communication, using social media wisely, how to accompany children to learn, and, 7) Problems faced in the implementation of the inspirational class program included how to determine the topic, finding parents willing and having time to be resource persons / motivators in the inspirational class.

Referring to the conditions and problems as described above, it was necessary to formulate a pattern or model of family involvement in the management of education that is innovative and reflects the synergy between parents and children in the family. The scope of the model was expected to: 1) describe in detail about the organization of family education, 2) optimize the teacher meeting with parents to equalize the view about the embedding of nationalism in children, 3) optimize parent classes to increase parents knowledge and skills in instilling nationalism in children 4) optimize inspiring classes to instil nationalism values in children and 5) optimize performances class to provide opportunities for the creation and appreciation of parents and children as a form of instilling the value of nationalism in children.

This model has been tested in 4 locations, namely Wiyata Bhakti Play Group in Purwakarta, POS PAUD Dewi Pramanik in Bandung Municipality, C Golden Age Kindergarten in Subang, and Public Kindergarden in Cimahi Municipality. The products include model scripts, dictates (patriotism, diversity, nationality), and media (posters, flipcharts, discussion cards).

\subsection{Purpose}

\subsubsection{General Purpose}

Creating a quality education ecosystem: at home, education units/schools, and in the community (environment) which encourages the instilling of nationalism value and a culture of achievement in children/ students, families, education units and the community.

\subsubsection{Spesific Purpose}

\subsubsection{For ECCE Student}

1) Providing non-academic impact, especially in instilling nationalism value and a culture of achievement

2) Providing academic impact, both directly and indirectly. 


\subsubsection{For Parents/ Families}

1) Increasing parents' capability in supporting and creating learning conditions for children at home or in the family, especially in instilling nationalism value

2) Increasing parents' participation in education units as a form of support to bring about a conducive, effective and quality education ecosystem

\subsubsection{For ECCE Units/Schools}

1) Improving education unit services to parents and children/ students

2) Promoting a more conducive, effective and quality education ecosystem

\subsubsection{For Communities/Environment}

1) Increasing public/ environmental awareness in supporting a conducive, effective and quality education ecosystem

2) Becoming a pilot/ inspiration for creating a conducive, effective and quality education ecosystem

\subsection{Family Involvement in Implementation Education in ECCE Units in Instilling Nationalism Values}

Family involvement in implementation education in ECCE units in instilling nationalism values is generally divided into 3 parts, namely inputs, processes, results and impacts. Inputs are empirical conditions, concepts and policies. Empirical conditions consist of conditions of students, parents, and education units. Empirical conditions of parents includes low parents participation in meeting organized by education units (dominated by mothers); there had not been alignment of education; the parents association passively initiated meetings, parents in meetings as listeners (one-way). Student conditions: the weakening of nationalism of the younger generation; the younger generation was less fond of national culture and considered as old-fashioned, preferred foreign cultures; individualistic attitudes, consumerism, were increasingly appearing in some societies. ECCE unit conditions: not yet optimal in carrying out 4 family engagement programs; school-andparent meetings were only conducted when report cards are distributed; parents' classes had not yet discussed the embedding of nationalism values, inspirational classes had not actively involved parents, class performances were only focused on children's appearance. The concept that became the model's input was family involvement in the ECCE unit. In the meantime, policy input is the Regulation of Minister of Education and Culture Number 30 of 2017 (Minister of Education and Culture of Indonesian Republic, 2018) and the Regulation of Directorate General of Early Childhood Education and Community Education Number 127 of 2017.
The process of family involvement in ECCE units in inculcating the value of nationalism was carried out in collaboration among tri sentra pendidikan (the three education center). The approach used was role modelling, clarifying values, and advocating for CIE. Role modelling means actions that can be imitated or emulated. Role modelling is a duty inherent in every parents naturally because of maturity in the children's daily life, especially when they are still in its infancy. In order to identify their personality, they still imitate a lot from their parents. Connected in the program of family involvement in instilling nationalism value, adults (educators, parents, school principals and the community) are people who are imitated and emulated by early childhood. Hasbullah stated that behavior, ways of doing, ways of speaking would be imitated by children. With this example a positive phenomenon is born by conforming with the person who is imitated. The positive identification is very important in rousing children's personality because exemplary is the main and most important educational tool, because the transfer process is tightly bound in the association among educators, parents, principals and the community with children and the association takes place naturally and intently. So in this dimension every educator, parent, principal and community must understand well that each child tends to identify himself/herself with someone close to his/her life.

The value clarification approach aims to raise awareness and develop the ability of children/ students to identify their own values and the values of others. Value clarification emphasizes how a person actually builds values which they consider to be good, so that in turn will inspirit their behavior in carrying out daily life in the community. The relationship between this approach and the family involvement program is very important because the embedding of nationalism values from an early age is grown and developed as a teaching way to shape early childhood in finding and determining nationalism values so that they are embedded in every child early.

Advocacy is a systematic and organized effort to influence and push for change by providing support and defending the weak. Advocacy itself is a science and art in strengthening and defending the problems that occur. The relation of advocacy with the family involvement is that the decline in nationalism values among adolescents/ youths is a problem, the solution of which must be found. Therefore, advocating communication, information and education early on is very important because in the golden age children begin to imitate, copy and feel what is done by adults. Besides, it is also to see the weak nature of children needed advocacy or reinforcement through communication, information and education to solve these problems.

Family engagement activities consisted of school-andparent meetings, parent classes, inspirational classes and classroom performances. The materials presented were positive parenting, educating in the digital age, embedding love for the motherland, the spirit of nationalism, respecting diversity. The parents classes were organized through seminars, field trips, and family gatherings. 
In the process, the teachers, educators, together with parents and community leaders were committed to conducting school-and-parent meetings, parent class activities, inspiring class activities, and performance activities. 1) School-and-parent meetings is the first meeting between the parents and the school, which is ideally conducted on the first day, because on the first day, parents mostly accompany take their children to school. The program aims to introduce parents to the environment and school programs, as well as the role that must be done by parents. In addition, it also aims to make schools hear the expectations and hopes of parents, agree on communication procedures between schools and parents, and form a forum for parents and school meetings periodically. This event serves a moment to inform school programs, including programs that involve parents such as family education programs. School-and-parent meeting also includes teacher-and-parent meetings, in which teacher(s) and parents discuss the development of children's education both academically and non-academically. 2) Parents' classes are places for parents to improve their ability to educate and nurture children so that positive character and culture of achievement grow. This program is not a compulsory program that must be followed by all parents, but it is expected that all parents of each class can participate in the class activities. Parents' representatives from each grades participating in this program are expected to be a motivator in family involvement for other parents. 3) Inspirational classes are activities involving parents/representatives/ professionals as a motivator or an inspiring figure for students at flag ceremony activities, celebrations, holidays and classrooms and in other related activities. The activities are also as a forum for mutual friendship among the parents involved to become resource persons or motivators, share stories and work experiences as well as motivation to achieve the purposes of their children 4. Performance event(s) is one of the student appreciation activities at school. The activities are carried out every semester and at the end of the year that are usually carried out by the school as a form of appreciation to students after taking one academic year.

The result of family involvement programs was the presence of parents' participation in the family involvement program in the Education unit, and the increase in knowledge, attitude, and competences of parents in instilling the value of nationalism.

The achievement of the family engagement program is supposed to have a positive impact on students by having the character of nationalism, and and the growth of love for the nation's culture.

All phases of model development, of course, need to be carried out continuously to make improvements and revision through a series of monitoring, assessment and assistance that leads to continuous quality improvement. The framework of the model as described above can be seen in the figure 1 .

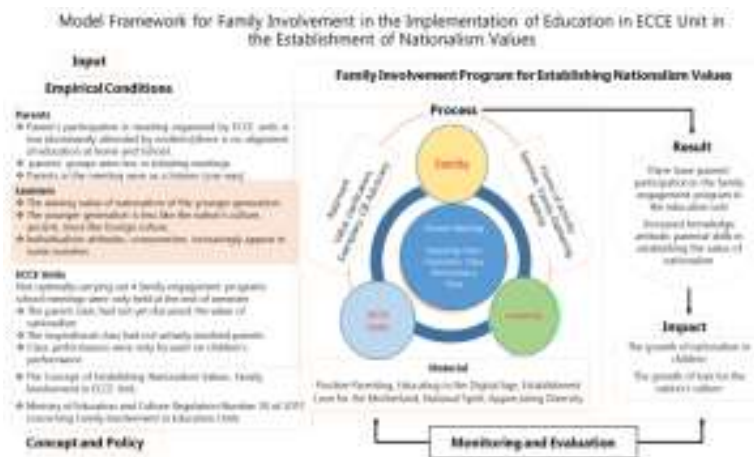

Figure 1 Phase of the model framework

\section{METHOD}

Family Involvement In The Implementation Of Education In The Early Childhood Unit In Instilling Nationalism Values applied research and development approach. Limitations regarding development research include, among others, Borg and Gall (1983) who states that development research is an attempt to develop and validate products used in education. Research and development approach was chosen because the purpose of the development was not intended to find theories, but rather to produce or develop a product, namely the manuscript of the model. The method used were the following:

1) Literature study (study of books and documents) regarding policies, concepts and theories, models, and reports related to the development of the model to be carried out.

2) Exploration study in the field regarding the exploration of problems, potentials and other information relating to the implementation of the program to be developed.

3) Discussion in order to formulate the substance of the model.

4) Expert/ resource validation with regard to the framework or design of the developed model and the resulting master model.

5) Field testing, by applying the draft model so that weaknesses, deficiencies and accuracy of the model model were known. Implementation tests were carried out through conceptual tests and operational tests with different locations.

\section{RESULT AND DISCUSSION}

\subsection{Results of Pretest and Post Test Differences of the Treatment Group}

To find out the results of the operational test, this study administered paired sample $t$ test analysis by comparing the Pretest with the Post Test result in the treatment group. Following are the results of the calculation of the paired sample $t$ test with 50 respondents $(n=50)$. 
Table 1 Paired sample t test results

\begin{tabular}{|c|c|c|c|c|c|c|}
\hline Group & Measurement & Average & Average Difference & n & t & Sig. $\mathbf{t}$ \\
\hline \multirow{2}{*}{ Treatment } & Pretest & 68,98 & $-11,48$ & \multirow{2}{*}{$\mathbf{5 0}$} & \multirow{2}{*}{9,773} & 0,000 \\
\cline { 2 - 7 } & Post Test & 80,46 & & & \\
\hline
\end{tabular}

Source: Primary data processed

Paired sample $\mathrm{t}$ test results with a total sample of 50 respondents $(n=50)$ showed that the treatment group obtained an average pretest value of 68.98 ; while the average Post Test was 80.46 ; meaning that the average difference between the Pretest and Post Test was 11.48. Based on the results of calculations using the $t$ test above the $t_{\text {count }}$ was 9,773 . The value of $t_{\text {table }}$ with $\mathrm{df}=\mathrm{n}-2=48$, and significance level $=0.05$, was 2.011. The test results indicated that the $\mathrm{t}_{\text {count }}$ was more than the $\mathrm{t}_{\text {table }}\left(\mathrm{t}_{\text {count }}=9,773>\right.$ $\left.\mathrm{t}_{\text {table }}=2,011\right)$ with the Sig. $\mathrm{T}<0.05$. It meant that there was a significant difference between the pretest scores and the post-test scores in the treatment group.

Decision: With Sig. $\mathrm{T}<\alpha=0.05$, and $\mathrm{t}=9.773>\mathrm{t}$ table $=$ 2.011 , so that $\delta \neq 0$, then Ho is rejected. Thus it can be concluded that family involvement has a significant influence on the instilling of nationalism value in the ECCE units.

\subsection{Conclusions on Data Analysis Results}

From the learning outcomes measured through the results of the pretest and post-test scores of respondents, the average value of the percentage of pretest and post-test both beginning and end showed an increase in the difference in treatment change. Based on the results of calculations using the $t$ test above, it can be calculated the percentage of the change. It indicated that there was a significant difference in the pretest scores with the post test scores in the treatment group. Thus it can be concluded that that family involvement has a significant influence on the instilling of the value of nationalism in the early childhood education units (love of the motherland, the spirit of nationality and respect for diversity).

\section{CONCLUSION}

\subsection{Conclusion}

The model of family involvement in the implementation of education in the early childhood unit in instilling nationalism values is an effort of the education unit and family in increasing parents' knowledge, attitudes, skills in embedding nationalism values to emerge children's nationalism and love of nation's culture.

The model is supposed to be beneficial for:

\subsubsection{Unit for early childhood education}

1) Contributing in accomplishing school programs

2) Collaboration occurs with parents

3) Bringing about the concept of tri sentra pendidikan (three education center)

4) Getting parents' support

5) Implementation of the nationalism value in ECCE units

\subsubsection{Parents}

1) Understanding the school program

2) Understanding how to assist children's learning at home

3) Supporting in realizing quality education units

4) Developing knowledge and skills to instill the nationalism in the family

Applying the instilling nationalism in the family

\subsubsection{Learners}

1) Encouraging discipline of learning

2) Encouraging character improvement

3) Creating culture of achievement

4) Implementing nationalism value in daily life

\subsubsection{The model can be successful if it meets the following requirements:}

1) The education unit is willing to be the trial location

2) Parents are willing to be involved in the program

3) The availability of educators who are in accordance with the qualifications and are competent,

4) The availability of facilities and infrastructure

5) The availability of financing

\subsection{Recommendation}

The Model of Family Involvement in the Implementation of Education in The Early Childhood Unit in Instilling Nationalism Values developed, needs to be improved both in substance and in its implementation strategy. Therefore, we consider that several things deserve the attention of all stakeholders.

Center for Development of Early Childhood and Community Education (PP PAUD and Dikmas) Jawa Barat needs to conduct socialization to district/ city education offices, to inform and get support for the implementation of 
models on a broader scale. It will be very meaningful, if the education office in each district/ city gives instructions to the early childhood education units (ECCE) to apply the model that has been developed

\section{REFERENCES}

Directorate General of Early Childhood Education and Community Education. (2018). Petunjuk teknis pelibatan keluarga pada penyelenggaraan Pendidikan. Jakarta: Directorate General of Early Childhood Education and Community Education

Minister of Education and Culture of Indonesian Republic. (2018). Petunjuk teknis pelibatan keluarga pada penyelenggaraan pendidikan di satuan pendidikan anak usia dini. Jakarta: Minister of Education and Culture of Indonesian Republic

Minister of Education and Culture of Indonesian Republic. (2017). Petunjuk teknis penguatan pendidikan karakter pada satuan pendidikan formal. Jakarta: Minister of Education and Culture of Indonesian Republic 